\title{
PROATIVIDADE E INOVAÇÃO: UMA REVISÃO INTEGRATIVA
}

\section{REVISÃO INTEGRATIVA}

BENTO, Amilton ${ }^{1}$

SILVA, Narbal ${ }^{2}$

BENTO, Amilton. SILVA, Narbal. Proatividade e inovação: Uma revisão integrativa. Revista Científica Multidisciplinar Núcleo do Conhecimento. Ano 06, Ed. 01, Vol. 08, pp. 68-84. Janeiro de 2021. ISSN: 2448-0959, Link de acesso: https://www.nucleodoconhecimento.com.br/administracao/proatividade-einovacao

\section{RESUMO}

Esse estudo teve como propósito verificar as interfaces entre a proatividade e a inovação. Por meio de uma revisão integrativa, procurou-se analisar a produção científica em periódicos nacionais sobre os dois fenômenos, entre os anos de 2006 e 2017, nos estratos de concentração do sistema Qualis/Capes A1, A2, B1 e B2 das áreas de conhecimento da Administração, Ciências Contábeis, Turismo e Psicologia. Após a identificação dos artigos, foram selecionados 100 documentos para o debate acerca dos relacionamentos entre os conceitos. Os resultados do estudo apontaram intersecções com o futuro, mudanças ambientais, competitividade e lideranças. No que tange às divergências, constatou-se que o comportamento proativo, ao contrário da inovação, pode ser considerado uma característica ou um traço de personalidade.

Palavras-chave: Proatividade, proativo, inovação.

\footnotetext{
${ }^{1}$ Doutorando em Psicologia, Mestre me Administração e graduado em Administração.

2 Orientador. Pós-Doutorado em Psicologia.
} 


\section{INTRODUÇÃO}

Diante de um cenário de acirradas disputas e constantes instabilidades mercadológicas, as organizações buscam endereçar suas forças para a inovação. Procuram criar valores inimitáveis (BARNEY, 1991), um olhar atento para as suas equipes de trabalho de forma a maximizar resultados. Nesse sentido, as empresas procuram desenvolver comportamentos proativos e positivos, ações que fomentem o pioreirismo na busca de alta performance e resultados favoráveis acima da média do mercado (CAMERON; SPREITZER, 2012; FRESE et al., 2014). Nesse contexto, destaca-se a proatividade e a inovação, temas frequentemente abordados por gestores e palestrantes, muitas vezes sem uma abordagem conceitual satisfatória, com definições variadas sem considerar as bases teóricas.

No que tange à proatividade, consta na literatura que vem se destacando ao longo do tempo no campo organizacional (JOHANESSENN; OLAISEN; OLSEN, 1999) seus aspectos antecipatórios e ligados à iniciativa das pessoas, impactam no desempenho (FRESE; FAY, 2001). No Brasil ainda existe dúvidas sobre sua definição e até mesmo executivos com cargos de lideranças não conseguem defini-la (BENTO, 2014). De acordo com Bateman e Crant (1993) a proatividade seria a tendência de propiciar, de forma estável, uma mudança ambiental. Além disso, consta na literatura que se manifesta com a substituição de chefias e cargos de lideranças (BENTO; SILVA, 2016; BENTO, 2014). Já a inovação, está relacionada à materialização das ideias, ao pioneirismo, na busca pela novidade e com isso obter vantagem competitiva. Nota-se na literatura associações conceituais entre esses fenômenos, porém sem análise pormenorizadas e demonstrações dessas relações. Assim, pretende-se, em função da inexistência do estabelecimento de relações mais profícuas entre os fenômenos, identificar possíveis relações conceituais entre a proatividade e inovação, com o debate inicial a seguir sobre a origem e conceito desses fenômenos.

\section{PROATIVIDADE}

O debate acerca da proatividade teve seu início na década de 60 , quando os estudos de Swietlik (1968) integraram os conceitos de personalidade de vários estudiosos, e 
as resumiu em "personalidade de reação ou personalidade proativa". Após estes estudos, somente na década de 90 outras pesquisas surgiram com duas abordagens diferentes acerca do tema. Nos Estados Unidos Bateman e Crant (1993), associaram o comportamento proativo às mudanças ambientais, enquanto na Europa, Frese e Fay (2001) discorriam que este tipo de comportamento se denominava de iniciativa pessoal, um comportamento no trabalho também chamado de auto partida, que se fundamentaria na persistência em superar os obstáculos na busca das metas e ações antecipatórias (FRESE; FAY, 2001).

Os autores anteriormente citados também distinguiram iniciativa pessoal do passivo tradicional. Esse último, conceituado como a parte reativa no trabalho, apenas respostas às demandas, enquanto a iniciativa pessoal é um conceito proativo pautado em agir com antecedência, que vai além da execução de tarefas. Seriam metas próprias definidas pelas pessoas, com foco em resolver problemas que ainda não ocorreram (FRESE, 2006; FRESE; FAY, 2001). Diante dessas duas vertentes de estudos, conclui-se que a proatividade pode ser entendida a partir de dois aspectos. O primeiro, nos estudos de Bateman e Crant (1993) concentrou nas características dos indivíduos com tendências a ações proativas visando mudanças. Já no segundo, coordenado por Frese e Fay (2001), pautado na iniciativa das pessoas, incide sobre os próprios comportamentos proativos, sendo estes antecipatórios e prospectivos.

Outras iniciativas no sentido de integrar estes conceitos são observadas na literatura (PARKER et al., 2006), segundo a visão desses último autores, as características da personalidade proativa e conceitos de iniciativa pessoal se entrelaçam. Além dessas definições, outros estudiosos defendem que a proatividade pauta-se em três pilares, a iniciativa pessoal dos indivíduos, os comportamentos proativos e a personalidade proativa (KAMIA; PORTO, 2009). Dada a importância desse comportamento, são observadas na literatura intervenções no sentido de desenvolver esse comportamento no âmbito individual e organizacional (FRESE et al., 2014) tal qual ocorre com a inovação, que a seguir será abordada. 


\section{INOVAÇÃO}

É unânime na literatura que o tema inovação foi apresentado no início do século XX por Shumpeter a partir da década de 1930, quando por meio da teoria do desenvolvimento econômico, debateu as diferenças entre invenção e inovação. Nesse contexto econômico, definiu que a inovação somente seria completa se ocorresse concomitantemente com a invenção e comercialização, tendo como consequência a riqueza (SCHUMPETER, 1988). Durante a década de 1990, através do manual de Oslo, a Organização para a Cooperação e Desenvolvimento Econômico (OCDE), definiu que inovar é implementar um novo produto ou serviço, melhorias ou um novo método para os negócios, tanto no local de trabalho como no meio externo (OECD, 2005).

Alguns autores defendem que inovação é a implementação de novas ideias (AMABILE, 1996; VAN DE VEM; ANGLE, 2000), que está associada à criatividade. Segundo Gava e Vidal (2009) para abordar o tema inovação é importante recordar duas correntes teóricas, a teoria neoclássica e a evolucionista. Os preceitos neoclassicistas pautam-se na racionalidade sem limites para o comportamento humano, visa relações econômicas equilibradas, já a ótica evolucionista deixa de considerar a objetividade, existe uma tendência ao dinamismo, a competitividade nos processos de produção para maximiza resultados (BELL; PAVITT, 1993).

A inovação tem sido considerada um fator crítico no quesito competitividade, está mais relacionada com a capacidade de inovação das organizações do que pelo ritmo de produção (BECATTINI, 1999; DESS; PICKEN, 2000). Alguns fatores são determinantes para a inovação, como as características pessoais dos atores envolvidos e o reconhecimento por parte da diretoria da necessidade de inovar (ROGERS, 1995; FRAMBACH; SCHILLEWAERT, 1999). Na visão de Hamel e Prahalad (1995), grande parte das organizações é reativa em seus processos não são proativas, analisam as mudanças e inovações ocorridas no mercado para posteriormente agirem. Isso leva a crer que uma organização com este perfil tende a ser seguidora do mercado em que atua, ou seja, espera as empresas concorrentes inovarem e após isso seguem o mesmo caminho imitando-as. 
Alguns estudos defendem que, para acompanhar o mercado do século $\mathrm{XXI}$, as organizações devem promover parcerias, não somente no âmbito comercial, mas de uma forma geral, o que envolve P\&D e abertura para as relações externas, no sentido de cooperação para propiciar vantagem competitiva (KAUFMAN; WOOD; THEYEL, 2000; MOGOLLÓN; VAQUERO, 2004). No Brasil, alguns estudos ocorreram com o objetivo de identificar fatores determinantes da inovação. Alguns resultados apontam que investimentos em recursos tecnológicos, alianças estratégicas com outras organizações, inovação aberta com pesquisas fora de seus domínios, podem indicar uma tendência à inovação (CABRAL, 2007).

Na sequência deste estudo será abordada a metodologia, o universo da pesquisa, a base de dados utilizada com os respectivos estratos pesquisados.

\section{ASPECTOS METODOLÓGICOS}

Por meio de revisão integrativa, buscou-se neste estudo reunir as publicações científicas brasileiras sobre os temas proatividade e inovação, bem como suas interfaces e conexões. A pesquisa foi realizada em periódicos nacionais certificados pelo Qualis/Capes das áreas de conhecimento da Psicologia, Administração, Ciências Contábeis e Turismo, todos vinculados aos estratos de qualidade de produção A1, A2, B1 e B2. Esta modalidade de pesquisa pode ser considerada de natureza descritiva com abordagem predominantemente qualitativa, que visa compreender os possíveis relacionamentos entre os fenômenos. No tocante ao procedimento de pesquisa utilizou-se de análise de documentos, considerados fontes secundárias de investigação e coleta. No que se refere ao alinhamento paradigmático, pode se associar ao paradigma interpretativista, relação próxima entre investigador e os fenômenos, que compartilha e integra o universo estudado (BURREL e MORGAN, 1979). Foram considerados para a pesquisa apenas os periódicos nacionais, o que totalizou 560 revistas, conforme representados na figura 1 que segue. 
Figura 1. Periódicos nacionais pesquisados por estrato

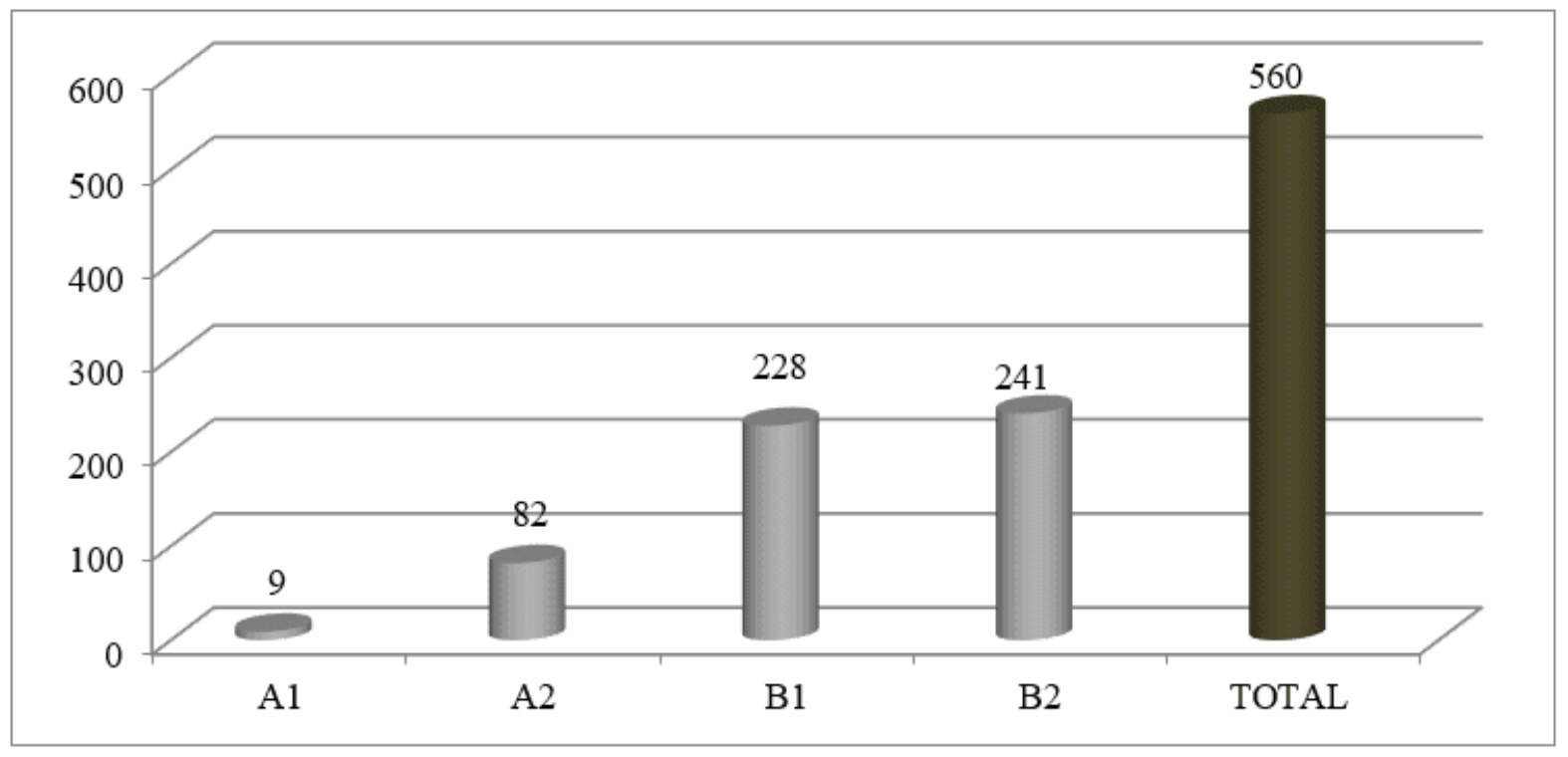

Fonte: Elaborado pelos autores

\section{PROCEDIMENTOS}

Após a localização dos periódicos, iniciou-se a pesquisa via internet localizando-se os sítios de cada periódico, nos quais os artigos foram coletados. No campo próprio de pesquisa de cada sítio, os artigos foram pesquisados por meio das palavras-chave: proatividade, proativo e inovação. Foram considerados para análise somente os artigos que continham as palavras-chave ou derivadas dessas, nos respectivos títulos, excluindo-se da relação os artigos que não atendiam esta condição. Foram encontrados 1.514 artigos que foram organizados por período de publicação para análise dos resumos. Após este procedimento, foram selecionados os 100 artigos por grau de relevância, segundo a visão dos pesquisadores. Os demais artigos figuraram apenas para a análise da evolução da produção científica dos anos 2006 a 2017.

Durante a pesquisa, algumas limitações foram encontradas, a primeira, diz respeito à relação dos periódicos do sistema qualis, que apresentava revistas repetidas e não raro, estavam presentes na relação de periódicos da área de psicologia e também na 
área da administração. Outra dificuldade observada, está relacionada a indisponibilidade dos artigos por parte de alguns periódicos, os quais permitiam acesso somente aos resumos. Diante dessas dificuldades, corre-se o risco de imprecisões nas análises quantitativas e a falta de abordagem, por dificuldades de acesso aos documentos não disponíveis.

\section{RESULTADO E DISCUSSÃO DOS DADOS}

Durante a pesquisa, observou-se que a maioria dos artigos encontrados se referia ao tema inovação. Já a proatividade raramente aparecia durante as buscas, evidências de escassez de publicações sobre o tema. Na sequência desta seção será apresentada por meio da figura 2 uma análise geral quantitativa das publicações encontradas sobre os dois temas.

Figura 2. Evolução geral das publicações a partir de 2006.

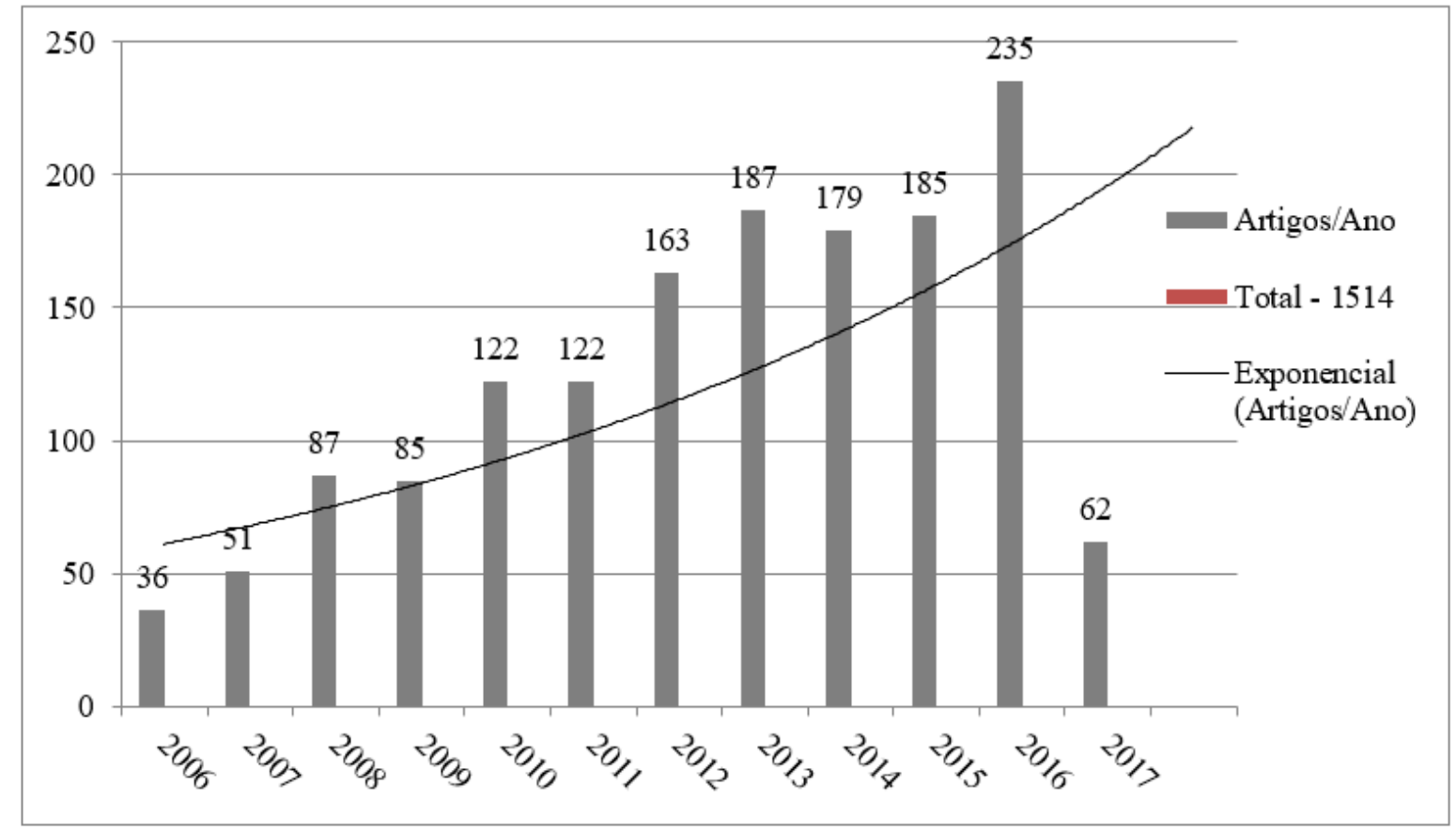

Fonte: elaborado pelos autores

Conforme demonstrado na figura 2, as publicações crescem anualmente, observouse uma notável produção a partir de 2006. Importante salientar que, os resultados de 
2017 referem-se até o mês de junho, portanto, não servem como parâmetros de análise com os anos anteriores. No campo da proatividade, conforme já discorrido anteriormente, a produção científica brasileira nos estratos pesquisados, é praticamente embrionária, apenas 9 artigos foram encontrados. A seguir na figura 3 será apresentada a análise gráfica quantitativa da produção científica sobre a proatividade, a qual evidencia o apontamento da baixa produção científica brasileira em torno deste construto.

Figura 3. Evolução das publicações sobre a proatividade

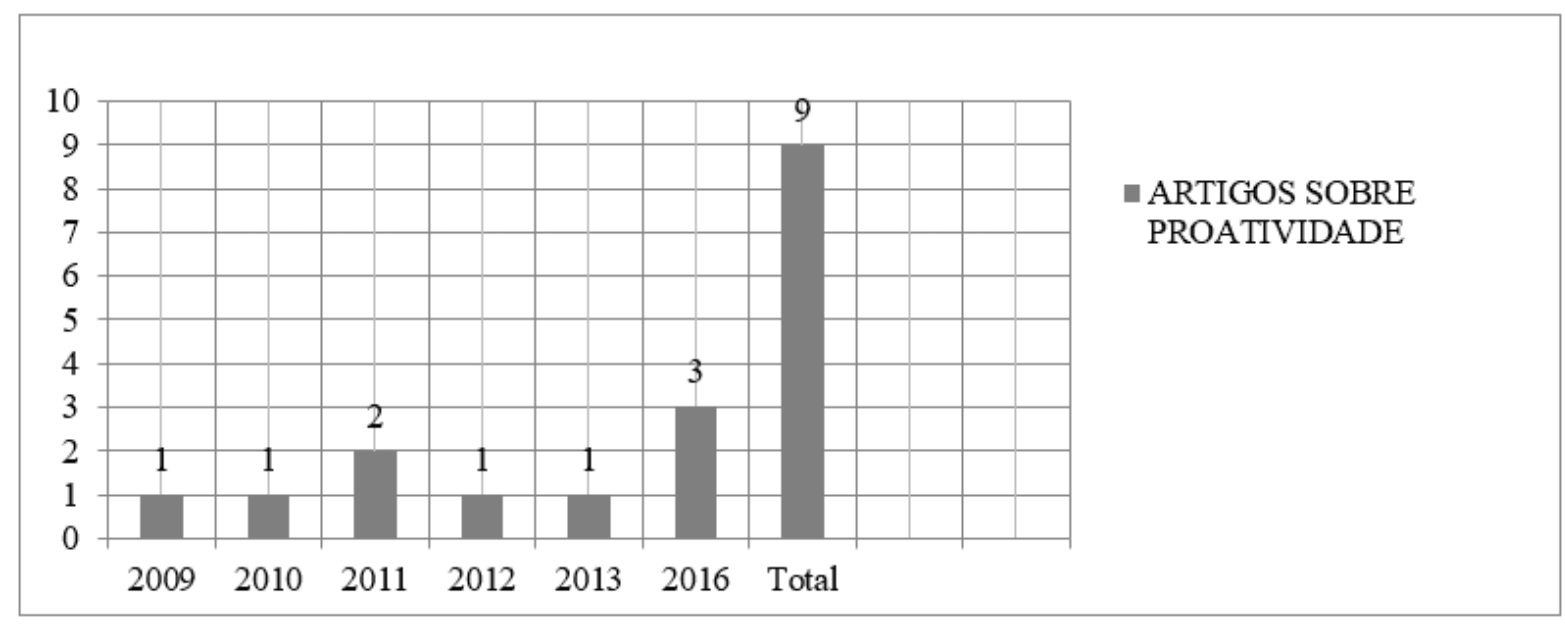

Fonte: elaborado pelos autores

Nota-se na figura 3, evidências da baixa produção acerca do tema proatividade, o que significa dizer que, a produção científica brasileira sobre o tema é bastante reduzida. Tal estágio incipiente pode indicar a necessidade de mais esforços para ampliar as pesquisas sobre o tema e com isso, diminuir as lacunas de estudos sobre o assunto. A seguir será analisada a literatura com evidências de associações entre os temas inovação e proatividade. 


\section{ANÁLISE DE CONTEÚDO ASSOCIANDO A INOVAÇÃO COM A PROATIVIDADE}

Na revisão bibliográfica é notável associações entre os construtos da proatividade e inovação, são observadas afinidades conceituais e ausência de debates acerca dessas relações. Ambos os construtos se relacionam com as mudanças ambientais, o futuro, competitividade no mercado e o papel das lideranças.

A proatividade e a inovação são retratadas na literatura como construtos ligados ao pioneirismo, como se antecipar e propor ao mercado projetos inéditos. Já na década de 1990, alguns autores mencionavam e consideravam como atitudes voltadas para o impacto futuro, foco em concretizar demandas ainda não percebidas (MORGAN, 1992; HAMEL; PRAHALAD, 1994; LUMPKIN; DESS, 1996). Essa relação com o futuro e longo prazo, também ocorre com o conceito de inovação, fenômeno este, que tem como um de seus pilares o pioneirismo, ou seja, chegar primeiro, tanto na criação de novos produtos, quanto na de serviços ou processos.

Diante disso, nota-se que, o destaque das ações antecipatórias e o vínculo com o futuro de ambos os fenômenos, podem ocasionar erros ou distorções de interpretação, inclusive confusão conceitual nas definições. A seguir no quadro 1 uma comparação conceitual entre os dois fenômenos que os vinculam ao futuro.

Quadro 1. Estudos que associam os fenômenos ao tempo

\begin{tabular}{|l|l|l|}
\hline Proatividade & Inovação \\
\hline $\begin{array}{l}\text { Posicionamento no sentido de criar } \\
\text { oportunidades e novas demandas, }\end{array}$ & $\begin{array}{l}\text { Para a criação de um ambiente } \\
\text { inovador é necessário o devido }\end{array}$ \\
possibilita identificar mudanças & preparo para as situações de \\
latentes e oportunidades a elas & mudanças, nas quais o tempo é \\
relacionadas, numa atitude de & considerado uma fonte de vantagem \\
antecipação (MORGAN, 1992). & competitiva em momentos intensos \\
& (STALK e HOUT, 1990).
\end{tabular}




\begin{abstract}
Demandas ainda não percebidas e $A$ inovação indica que algo foi concretizadas através de ações inventado, descoberto e projetado, antecipatórias (HAMEL e PRAHALAD, por antecedência. Mudanças 1994). importantes nos produtos, serviços e processos (MOTTA,1989).

Habilidade de antecipação e ação premeditada sobre o futuro, tomada de A inovação possui como um de seus iniciativa no sentido de modelar o significados a introdução de alguma ambiente (LUMPKIN e DESS, 1996). novidade em um ambiente de

\section{A proatividade pode ser percebida pela} quantidade e frequência com que Movimento de mudanças em direção à disponibiliza novos produtos, serviços e qualidade e produtividade (CUBAS, processos e recursos dedicados à 2009). inovação (KAMIA e PORTO, 2011).
\end{abstract}

Fonte: elaborado pelos autores.

Diante de tais posicionamentos, nota-se que existem indícios de que ambos os fenômenos estejam ligados ao futuro com relação estreita com tempo, a intenção de chegar primeiro que o concorrente, de se antecipar e do pioneirismo, como se fosse uma tentativa de materializar o futuro no presente (HAMEL; PRAHALAD, 1994), sendo que, o fator "tempo" pode ser determinante no sucesso das ações, assim como as mudanças ambientais, suas incertezas e tolerância aos erros referenciadas na sequência.

\title{
O RELACIONAMENTO DA PROATIVIDADE E INOVAÇÃO COM AS MUDANÇAS AMBIENTAIS, MOMENTOS DE INCERTEZAS E TOLERÂNCIA AO ERRO
}

A literatura aponta que a base das mudanças ambientais é resultada de ações proativas e inovativas (JOHANESSENN et al., 1999; BATEMAN; CRANT, 1993). As mudanças em função da inovação são impulsionadas principalmente pela indústria 
da tecnologia (BENNIS 1976; DAMANPOUR, 1991). Já as mudanças envolvendo a proatividade são percebidas após as instabilidades ambientais, exemplos disso são mudanças em cargos de comando, como os cargos de gerência de topo, diretores ou funções similares com impacto positivo na performance e na produtividade (BENTO; SILVA, 2016; GRIFFIN; NEAL; PARKER, 2007).

As organizações proativas e inovadoras possuem como características comuns, a capacidade de perdoar e tolerar os erros, sinais de lideranças que permitem 0 experimento e a possibilidade de errar destituída de punição. Estudiosos apontaram que relevar erros e situações de insucesso em busca de melhorias, são variáveis no processo de inovação (SLOANE, 2006).

$\mathrm{Na}$ sequência deste estudo, através do quadro 2, será enfatizada a relação da proatividade e inovação com estes aspectos abordados anteriormente.

Quadro 2. Estudos que associam os fenômenos às mudanças, momentos de incertezas e tolerância ao erro.

\begin{tabular}{|c|c|}
\hline os sobre Proativi & Estudos sobre Inovação \\
\hline $\begin{array}{l}\text { Comportamento proativo está } \\
\text { associado às mudanças ambientais } \\
\text { (JOHANESSENN et al., 1999). }\end{array}$ & $\begin{array}{l}\text { As formas mais comuns de se perceber } \\
\text { uma mudança global é por intermédio } \\
\text { da inovação tecnológica (BENNIS, } \\
\text { 1976). }\end{array}$ \\
\hline $\begin{array}{l}\text { O indivíduo proativo causa } \\
\text { interferência no ambiente do qual faz } \\
\text { parte, sem se limitar as forças } \\
\text { situacionais (BATEMAN; CRANT, } \\
\text { 1993). }\end{array}$ & $\begin{array}{l}\text { Inovar é mudar uma organização, ações } \\
\text { no sentindo de responder } \\
\text { aos ambientes internos e externos ou } \\
\text { ações para influenciá-los. } \\
\text { (DAMANPOUR, 1991). }\end{array}$ \\
\hline $\begin{array}{l}\text { O comportamento proativo também } \\
\text { foi evidenciado após mudanças em } \\
\text { cargos de comando, que pode ter } \\
\text { relação positiva com a performance e }\end{array}$ & $\begin{array}{l}\text { Independente dos formatos das } \\
\text { transformações das organizações, } \\
\text { estas somente entenderão as mudanças } \\
\text { se compreenderem as modificações } \\
\text { ambientais, ligadas aos seus valores, }\end{array}$ \\
\hline
\end{tabular}


produtividade (BENTO; SILVA, 2016; produtos, tecnologias e anseios GRIFFIN et al., 2007). (CAVALCANTI, 1979).

A proatividade pode alterar o cenário, Ambientes inovadores valorizam a já que está ligada a contextos de importância de saber agir em ambientes incertezas, assumindo o controle da de alta competitividade e turbulentos situação que pode resultar em (BASTOS et al., 2007).

impactos positivos no desempenho

(GRIFFIN et al., 2007).

Tolerar os erros é relevante para Uma postura inovadora depende de um fomentar a experimentação, ambiente favorável, pessoas criativas e características de empresas sem medo de errar (SERRA et al., proativas. Relevar erros e situações 2007).

de insucesso são variáveis no processo de inovação (SLOANE, 2006; KUMAR, 2004).

Fonte: elaborado pelos autores.

Essa relação próxima entre a proatividade e mudanças ambientais pode também influenciar a inovação. Influências ambientais podem gerar mudanças e novas formas de atuação, um ambiente pautado na confiança, liberdade de criação e tolerância às ações de insucesso fomenta a criatividade, faz com que o corpo funcional se exponha com maior frequência, evitando um comportamento passivo e inerte (KUMAR, 2004; SLOANE, 2006; SERRA et al., 2007).

Além dessa questão ambiental, também se observa impactos das lideranças nos construtos da proatividade e inovação mencionados a seguir.

\section{O RELACIONAMENTO DA PROATIVIDADE E INOVAÇÃO COM AS LIDERANÇAS}

A compatibilidade e relações entre os fenômenos em questão, também são observadas quando se estuda o papel das lideranças, a influência desses atores 
nesses processos. De acordo com Crant (1996) pessoas proativas mostram iniciativa, antecipam e solucionam problemas, são ativas, se envolvem em redes interpessoais de trabalho para potencializar suas carreiras, características de líderes ou futuros líderes organizacionais. Um processo de inovação não se trata apenas de evolução técnica. Segundo Giget (1997) as inovações mais impactantes nas organizações advêm de recursos humanos, financeiros, na troca de conhecimento e de relações entre departamentos, pode-se acrescentar a isso as relações estabelecidas entre lideranças e liderados.

Alguns estudos apontam como fundamental a participação das lideranças no processo de inovação, suportado também por recursos que vão além de recursos financeiros como: o capital humano, as próprias lideranças e cultura organizacional (BRAVOIBARRA; HERRERA, 2009). A proatividade está presente no empreendedorismo, representada por seus executivos e na iniciativa de seus principais líderes. Estudos recentes demonstram o alto grau de proatividade nos cargos considerados de alta gerência, como líderes de departamentos ou direção, sendo entre os pesquisadores, um conhecimento bem sedimentado, o qual reconhece as lideranças como agentes essenciais de proatividade (ARGYRIS, 1966; GAVA, 2009; BENTO; SILVA, 2016; BENTO, 2014). A inovação pode ser fruto de um processo de aprendizagem, resultante do envolvimento dos principais atores, ou seja, dos seus principais líderes, passando de um modelo linear para um modelo de interações, sem isolamento, mas um processo de aprendizagem coletivo (LUNDVALL, 2005; KEEBLE; WILKINSON, 1999).

Para que ocorra um ambiente proativo e inovativo, o corpo funcional das organizações precisa de amparo dos principais gestores, tolerância de eventuais insucessos na busca do acerto, assegurar recursos para a implementação de estratégias proativas no ambiente de negócios (GAVA, 2009). Diante disso, a seguir no quadro 3, estudos que associam a proatividade e a inovação às lideranças organizacionais. 
Quadro 3. Estudos que associam os construtos proatividade e inovação às lideranças organizacionais

\begin{tabular}{|c|c|}
\hline Estudos sobre Proatividade & $\begin{array}{l}\text { Estudos } \\
\text { Inovação }\end{array}$ \\
\hline $\begin{array}{l}\text { Estudos recentes demonstram o alto grau de proatividade } \\
\text { nos cargos considerados de alta gerência, como líderes } \\
\text { de departamentos ou direção, sendo entre os } \\
\text { pesquisadores, um conhecimento bem sedimentado } \\
\text { reconhecendo as lideranças como agentes essenciais de } \\
\text { proatividade (ARGYRIS, 1966; GAVA, 2009; BENTO; } \\
\text { SILVA, 2016; BENTO, 2014). }\end{array}$ & $\begin{array}{l}\text { Os líderes internos } \\
\text { são os principais } \\
\text { responsáveis pelos } \\
\text { caminhos adotados } \\
\text { rumo a inovação } \\
\text { (ABERNETHY; } \\
\text { BOUWENS; LENT, } \\
\text { 2010). }\end{array}$ \\
\hline & $\begin{array}{l}\text { A inovação pode ser } \\
\text { fruto de um processo } \\
\text { de aprendizagem, } \\
\text { resultante do } \\
\text { envolvimento dos } \\
\text { principais } \\
\text { atores, } \\
\text { isolamento, mas um } \\
\text { processo de } \\
\text { aprendizagem } \\
\text { coletiva (LUNDVALL, } \\
\text { 2005; KEEBLE e } \\
\text { WILKINSON, 1999). }\end{array}$ \\
\hline $\begin{array}{l}\text { Para que ocorra um ambiente proativo o corpo funcional } \\
\text { das empresas precisa de amparo dos principais } \\
\text { gestores (GAVA, 2009). A proatividade se relaciona } \\
\text { com as lideranças transformacionais (BATEMAN; } \\
\text { CRANT, 1993). }\end{array}$ & $\begin{array}{lr}\text { Líderes } & \text { buscam } \\
\text { disseminar } & \text { um } \\
\text { sentimento } & \text { de } \\
\text { cumplicidade } \quad \text { e } \\
\text { coletividade }\end{array}$ \\
\hline
\end{tabular}


Fonte: elaborado pelos autores.

Dentre os fatores citados, referentes a relação entre proatividade e inovação, as principais lideranças estão entre os que mais contribuem para sedimentar essa associação, a literatura anteriormente citada corrobora essa afirmação. As organizações são reflexos de seus gestores e dos demais trabalhadores, em especial, de suas ações no ambiente externo e de suas capacidades de previsibilidade. Para Morgan (1992), os limites da competição no mercado e do ambiente organizacional internos são reflexos das gerências de topo.

Diante desses pontos comuns entre proatividade e inovação, nota-se também aspectos divergentes, os quais serão elencados e debatidos na sequência deste estudo.

\section{PONTOS DIVERGENTES ENTRE PROATIVIDADE E INOVAÇÃO}

Além das afinidades entre esses fenômenos, existem diferenças importantes que devem ser ressaltadas. A proatividade pode ser associada às características individuais ligadas à personalidade humana e questões situacionais. Algumas pesquisas demonstraram relações positivas nesse sentido. Exemplo disto são os estudos de Bateman e Crant (1993), que relacionaram a escala de personalidade proativa com neuroticismo, extroversão, abertura para novas experiências, socialização e realização. Já em outras pesquisas foram encontradas relações positivas com a questão comportamental e forças situacionais como: necessidade de realização; orientação para agir; estratégias de enfrentamento; planejamento de carreira; cognição e tendências comportamentais dos indivíduos em alterar o ambiente (FRESE et al., 1997; FRESE; FAY, 2001).

Diante disso, nota-se que a proatividade possui grande afinidade com as características pessoais dos envolvidos, sem correspondência com a definição macro 
da inovação. Isto porque, esta poderá acontecer por vários motivos, entre eles às questões mercadológicas, as necessidades internas e externas das organizações. Desde que Schumpeter (1961) definiu a inovação como sendo novas combinações de recursos que propicia a geração de bens e novidades na organização industrial, parece não haver dúvidas acerca do conceito. Este estudo, mostra que os conceitos de inovação e proatividade diferem entre si, porém existem relações e indícios de que a proatividade pode ser classificada como um antecedente da inovação, atuando como uma mola propulsora nesse processo.

\section{CONSIDERAÇÕES FINAIS}

O estudo realizado por meio desta revisão integrativa, procurou verificar a realidade científica brasileira, bem como as relações conceituais entre proatividade e inovação. Nota-se que a reduzida produção nacional sobre a proatividade evidencia a necessidade de intensificar estudos sobre o tema e retratar a realidade nacional de nossas organizações, sejam elas públicas, privadas ou não governamentais. No que se refere à inovação, existe um quadro bem diferente se comparado ao da proatividade, vários estudos foram identificados, com destaque para a área de tecnologia, saúde e educação. No tocante a contribuição, a presente pesquisa apresenta considerações relevantes para a área da administração e psicologia, evidencia muitos estudos sobre inovação e apresenta um quadro incipiente de pesquisas sobre o construto da proatividade.

Além disso, foram apresentadas relações importantes entre a inovação e proatividade, afinidade com a previsibilidade, o futuro, mudanças ambientais, e congruência quando abordado o papel das lideranças. Também foram identificados pontos divergentes entre os temas, sendo a inovação um movimento organizacional que materializa ideias, apresenta ao mercado novos produtos e novas formas de fazer as coisas. Já a proatividade possui duas vertentes, uma disposicional estável, baseada nas características individuais e outra baseada em fatores ambientais, sendo este também um fator que desperta este comportamento. 
Diante dessas contribuições, este estudo pode ser fonte de inspiração para novas pesquisas, ampliar o debate em torno da proatividade e suas relações com outros construtos, como por exemplo, analisar suas congruências com as forças do capital psicológico positivo, este formado pelo otimismo, esperança, autoeficácia e resiliência. Recomenda-se também que novos estudos sejam efetuados em outras bases de dados, já que este ficou restrito à base Qualis/capes, pode ser estendido para bases como Scielo e Ebsco.

\section{REFERÊNCIAS}

ABERNETHY, M. A.; BOUWENS, J. ;VAN L. Leadership and control system design. Management Accounting Research, 21(1), 2-16, 2009. Em: http://hdl.handle.net/11343/29503

AMABILE, T. Creativity and innovation in organizations. Harvard Business School, 5, $1-15,1996$.

ARGYRIS, C. Interpersonal barriers to decision making. Harvard Business Review, (44), 84-97, 1996. Em: https://hbr.org/1966/03/interpersonal-barriers-to-decisionmaking

BARNEY, J. Finn Resources and Sustained Competitive Advantage. Journal of Management, $\quad$ 17(1), $99-120, \quad 1991 . \quad$ Em: http://www.furb.br/web/upl/editais/201510051116180.Barney.pdf?20151029113238

BASS, B. M. The bass handbook of leadership: theory, research e managerial applications (4th. ed.). New York: Free Press, 2008.

BASTOS, A. V. B.; SOUZA, J. J.; MENEZES, I. G.; NERIS, J. S.; MELO, L. C. T.; BRANDÃO, L. A. G.Teoria implícita de organização e padrões de inovação nos processos de gestão. Psicologia: Reflexão \& Crítica, 20(1), 157-166, 2007.

BATEMAN, T. S.; CRANT, J. M.The proactive component of organizational behavior: a measure and correlates. Journal of Organizational Behavior, 14(2), 103-118, 1993. 
BECATTINI, G. Os distritos industriais na Itália. In: Urani, André et al. Empresários e empregos nos novos territórios produtivos: o caso da Terceira Itália. Rio de Janeiro: DP\&A, 1999

BELL, M.; PAVITT, K. Technological accumulation and industrial growth: contrasts between developed and developing countries. Industrial and Corporate Change, 2(2), 157-211, 1993.

BENNIS, W.G. Organizações em mudanças. São Paulo: Atlas, 1976.

BENTO, A. Proatividade de mercado: uma análise do setor de papel e celulose brasileiro. Dissertação de Mestrado, Universidade do Sul de Santa Catarina, 2014. Em:

https://riuni.unisul.br/bitstream/handle/12345/432/110384_Amilton.pdf?sequence=1\&i sAllowed=y

BENTO, A; SILVA, N. Comportamento proativo nas organizações: Uma análise do desempenho dos clubes do futebol brasileiro em função das trocas constantes da comissão técnica. Boletim Academia Paulista de Psicologia, 36(90), 2016. Em: http://pepsic.bvsalud.org/scielo.php?script=sci_abstract\&pid=S1415-

$711 X 2016000100012$

BRAVO-IBARRA, E. R.; HERRERA, L. Capacidad de innovación y configuración de recursos organizativos. Intagible Capital, 5(3), 301-320, 2009. Em: http://www.redalyc.org/html/549/54912879005/

BURREL, G.;MORGAN, G. (1979). Sociological Paradigms and Organizacional Analysis. Heineman: London, 1979.

CABRAL, J.E.O. Determinantes da Propensão para Inovar e da Intensidade Inovativa em Empresas da Indústria de Alimentos do Brasil. RAC -Revista de Administração Contemporânea, 11(4), 87-108, $2007 . \quad$ Em: http://www.redalyc.org/pdf/840/84011404.pdf 
CAMERON, K. S.; SPREITZER, G. The Oxford handbook of positive organizational scholarship. Oxford: Oxford University Press. (Eds.), 2012.

CAVALCANTI, B.S. Considerações sobre seus objetivos, valores e processos. Revista de Administração Pública, 3(2), 49-84, 1979 Em: http://bibliotecadigital.fgv.br/ojs/index.php/rap/article/view/7510/5974

CRANT, J. M. The proactive personality scale as a predictor of entrepreneurial behavior. Journal of Small Business Management, 34, 42-49, 1996.

CUBAS M.R. Instrumentos de inovação tecnológica e política no trabalho em saúde e em enfermagem: a experiência da CIPE®/CIPESC. Rev Bras Enferm, 62(5), 745-747, 2009.

DAMANPOUR, F. Organizational innovation: analysis of effects of determinants and moderators. Academy of Management Journal, 34(3),555-590, 1991.

DESS, G. G.; PICKEN, J. C. Changing roles: leadership in the 21st century'. Organizational Dynamics, 28, 18-34, 2000.

FRAMBACH, R. T.; SCHILLEWAERT, N. Organizational innovation adaption: a multilevel framework of determinants ans opportunities for future research. Institute for the Study of Business Marketers - Report 29. The Pennsylvania State University, 1999.

FRESE, M.; FAY, D.; HILBURGER, T.; LENG, K.; TAG, A. The concept of personal initiative:Operationalization, reliability and validity in two German samples. Journal of Occupationaland Organizational Psychology, 70(2), 139-161, 1997.

FRESE, M.; FAY, D. Personal initiative (PI): An active performance concept for work in the 21st century. Research in Organizational Behavior, 23, 133-187, 2001.

FRESE, M. Grand theories and mid-range theories: Cultural effects on theorizing and the attempt to understand active approaches to work. In: Smith, K. G.; Hitt, M. A. (Eds.). Great minds in management: The process of theory development. Oxford: Oxford University Press, 84-108, 2006. 
FRESE, M. et al. Increasing personal initiative in small business managers/owners leads to entrepreneurial success: A theory-based controlled randomized field intervention for evidence based management. Academy of Management Learning \& Education, v. 13, p. 354-379, 2014.

GAVA, R. Proatividade de mercado: construção de um modelo teórico. Tese de Doutorado, Universidade Federal do Rio Grande do Sul, Porto Alegre, 2009.

GAVA, R.;VIDAL.W.J.R. Sistema de Inovação em Nível de Firma: Evidências de uma Iniciativa no Mercado Brasileiro de Telecomunicações. Rac-eletrônica, 3(1), 180-201, 2009.

GIGET, M. Techonology, innovation and strategy: recent developments. International Journal of Technology Management, 14(6-7-8), 613-634, 1997.

GRIFFIN, M. A.; NEAL, A.; PARKER, S. K. A new model of work role performance: Positive behavior in uncertain and interdependent contexts. Academy of Management Journal, 50, 327-347,2007.

HAMEL, G.;PRAHALAD, C. K. Competing for the future. Boston, MA: Harvard Business Scholl Press, 1994.

HU, J.; WANG, Z.; LIDEN, R. C.; SUN, J. The influence of leader core self-evaluation on follower reports of transformational leadership. The Leadership Quarterly, 23(5), 860-868, 2012.

JOHANESSENN, J.; OLAISEN, J.; OLSEN, B. Managing and organizing innovation at the knowledge economy. European Journal of Innovation Management, 2(3), 1999.

KAMIA, M.; PORTO, J.B. Comportamento Proativo nas Organizações. O Efeito dos Valores Pessoais. Psicologia:ciência e profissão, 31(3), 456-467, 2011.

KAMIA, M.; PORTO, J. B. Desenvolvimento e validação da Escala de Comportamento Proativo nas Organizações - ECPO. Revista de Avaliação Psicológica, 8(3), 359-367, 2009. 
KAUFMANN, A.; WOOD, C.; THEYEL, G. Collaboration and technology linkages: a strategic supplier typology. Strategic Management Journal, 21(6), 649-663,2000.

KEEBLE, D.; WILKINSON, F. Collective learning and knowledge development in the evolution of regional clusters of high technology SMEs in Europe. Regional Studies, 33(4), 295-303, 2009.

KUMAR, N. Marketing as strategy: understanding the CEO's agenda for driving growth and innovation. Boston, MA: Harvard Business School Press, 2004.

LUMPKIN, G. T.; DESS, G. G. Clarifying the entrepreneurial orientation construct and linking it to performance. Academy of Management Review, 21(1), 135-172, 1996.

LUNDVALL, B. National innovation systems: analytical concept and developmenttool. In: Druid summer conference. Proceedings... Copenhagen, 2005. Em: www.druid.dk MOGOLLÓN, R. M. H.;VAQUERO, A. C. El comportamiento innovador y los resultados de la empresa: un análisis empírico. In: Congreso hispano-francês de aedem, 14.,Ourense. Memorias. Madrid: Academia Europea de Dirección y Economía de la Empresa, 739-750, 2004.

MORGAN, G. Proactive Management. In.: Mercer, D. Managing the external environment: a strategic perspective. Londres: Sage Publications, 1992.

MOTTA, P. R. Gerência de idéias novas: como despertar a criatividade e vencer a impotência do desejo inovacional? Revista de Administração Pública, (4), 71-86, 1989.

OECD. Handbook on Economic Globalisation Indicators, OECD, Paris, 2005.

PARKER, S. K.;WILLIAMS, H. M.;TURNER, N. Modeling the antecedents of proactive behavior at work. Journal of Applied Psychology, 91(3), 636-652,2006.

ROGERS, E.M. Diffusion of Innovations. (4th. ed.). New York: Free Press,2005. 
SCHUMPETER, J. Capitalismo, socialismo e democracia. Rio de Janeiro: Fundo de Cultura, 1961.

SCHUMPETER, J. Teoria do desenvolvimento econômico: uma investigação sobre o lucros, capital, crédito, juros e o ciclo econômico. São Paulo: Nova Cultural, 1988.

SERRA, F. A. R.; FIATES, G. G.;ALPERSTEDT, G. D.Inovação na pequena empresa: um estudo de caso na Tropical Brasil. Journal of Technology Management \& Innovation, 2(2), 170-183, 2007.

SLOANE, P. The leader's guide to lateral thinking skills: unlocking the creativity \& innovation in you \& your team. London-Filadelfia: Kogan-Page, 2006.

STALK, G.; HOUT, T. Competing against time: how time-based competition is reshaping global markets. New York: Free Pres,1990.

SWIETLIK, E. The reacting or proactive personality? Studia Socjologiczne, 2, 209-218, 1968.

VAN DE VEN, A. H.; ANGLE, H. L. An introduction to the Minnesota innovation research program. In: A. H. Van De Ven, H. L. Angle, \& M. S. Poole (Eds.). Research on the management of innovation: the Minnesota studies. New York: Oxford University Press, 2000.

Enviado: Dezembro, 2020.

Aprovado: Janeiro, 2021. 